\title{
Understanding the lives of multiple-birth families: Listening to the voices of parents and professionals
}

\author{
Heinonen Kristiina ${ }^{1,2 *}$ \\ ${ }^{1}$ Teacher of Nursing, Savo Vocational College, Kuopio, Finland \\ ${ }^{2}$ Department of Nursing Science, University of Eastern Finland
}

\begin{abstract}
Background A literature review showed that there has been some research on parenting of multiples, but there is a need to study how professionals work with multiple-birth families in different nursing contexts.

The aim of this article is to open up some aspects of the daily lives and needs for support of multiple-birth families from the perspectives of parents of twins ( $\mathrm{n}=12$ ), public health nurses $(n=8)$ and family care workers $(n=11)$ and to contribute to the understanding of such families.

Methodology This qualitative research study is based on phenomenological hermeneutics. The data comprise the participants' interviews, written documents and the researcher's notes.

Results The phenomena of the lifeworld of multiple-birth families and their needs for support as described by parents are: "A state of constant vigilance”, "Ensuring that they can continue to cope" and "Opportunities to share"; as described by public health nurses: "Recognizing the strain", "Lightening the load of daily life" and "Targeting special needs"; as described by family care workers: "Support with coping", "Making use of special information" and "Bringing security". This article deals with some of these aspects.

Conclusions Multidisciplinary collaboration should be strengthened and utilized with this client group. To gain understanding of and develop better nursing support for multiple-birth families, the voice of parents should be listened to. Special programs and simulation pedagogy could be used to train students and professionals and reinforce their knowledge base. Information is required that is specific to the needs of multiple-birth families.
\end{abstract}

\section{Introduction}

Phenomenology is the philosophical name for the method of investigating or inquiring into the meaning of human beings' lived experiences. The present study is based on qualitative research and is guided by phenomenological hermeneutics, using [1] method to describe the lifeworld and the needs for support of multiple-birth families as expressed by parents of twins and social and health care professionals. Phenomenological research involves the study of the lived experiences of individuals related to a concept or phenomenon. Phenomenology is the reflective study of pre-reflective or lived experiences, and it focuses on interviewing in order to gain understanding of the meaning of the participant's experiences [1-4].

Multiple-birth families have twins, triplets, or more [5,6]. A systematic literature review revealed that research on this topic has been done since the 1980s. There is a need for research focusing on fathers [7-10] and social and health care professionals working with multiplebirth families [9]. The interest of previous multiple-birth family studies has been on the transition into parenthood [11] pregnancy and mothering multiples [12-15], parenthood [8,9,12,13,16], care giving [9,10,12,13,17] twins' sleeping [18-21] and the interactions and relationship between mother and twins and between twins themselves [22-24].

\section{Background}

At the beginning of pregnancy, parents of twins have a special status and need to be aware of the risks of pregnancy and childbirth $[22,25,26]$. Harvey ME, et al. [15] state that parents of preterm infants await advice, guidance, and support from professionals. The situation is more challenging for the parents if multiple-birth children are born prematurely, born through a Cesarean section or are taken into hospital care $[14,26]$. If there is a situation where the infants have to be separated due to differences in medical status, it could create practical and psychological problems during the neonatal period [26]. Holditch-Davis D, et al. [10] describe the experiences of parents of multiple-birth infants in the early weeks after delivery, which include: the specialness of multiples both positive and negative, the difficulties involved in managing more than one infant, and general attachment concerns. There is a need for emotional support and guidance on how to organize daily life and take care of several infants demanding the parents' attention simultaneously. However, other people can also help them manage their situation and organize their life after birth [8,9,27], while the neonatal period is especially an important time to prepare parents for such parenthood and life [8,9]. Nurses are vital to assessing the needs of multiple-birth families, coordinating various services and providing ongoing support [28]. Bryan E also stresses the importance of educating families before, during, and after a multiple birth [29].

Correspondence to: Heinonen Kristiina, Teacher of Nursing, Savo Vocational College, Kuopio, Finland, E-mail: tkheinon@uef.fi

Key words: phenomenology, hermeneutics, van Manen, multiple-birth family, twins, family nursing, social and health care professionals

Received: December 04, 2017; Accepted: December 20, 2017; Published: December 23, 2017 
Many researchers have found that it is challenging for parents to cope in general with more than one same-age child in daily life [8$10,15-17,27,30,31]$. Previous research shows that support is needed in facilitating a mother's ability to develop a relationship with each twin [30]. If a mother consciously tries to find differences between her multiple infants from the moment of their birth, the children feel clear about their own identities [27]. The individualisation and equal treatment can be challenging for parents [15,30,31-33]. The challenges the mothers faced included the impact of a multiple birth on family life, the impact of preterm birth, coping and adapting to being parents of twins particularly in the first year, the mismatch between support needed and support received, and the impact of all these factors on the health and wellbeing of themselves, their children and their family [15].

Having twins presents parents with a different kind of challenge in establishing an interactive relationship with the children in comparison with children of different ages [25,34]. Usually, when a child is being cared for, the mother or father is with the child, so they are in a dyadic relationship. In caring for twins, the mother or father has to divide their attention simultaneously between the two children, so the interaction is at least three-way (triad) with at least one speaker and two listeners $[22,25,32,33]$. The triadic relationship affects both the establishment of interaction between mother and child and the mother's caring behaviour $[24,35]$. Because of the lack of one-to-one time and continual interruption of the interaction, the parents' speech to the child may be qualitatively and quantitatively simpler $[26,36,37]$. Moreover, mothers have been observed to leave their children for longer periods in the care of others, to hold the children in their arms less and to talk to the children less in comparison with the mothers of singletons [10]. Younger women with low incomes, infertility history, great self-esteem, who had experienced quickening and were in an advanced stage of pregnancy, reported greater prenatal attachment to their twins [25]. However, [38] results yielded a difference in maternal attachment between twins and singletons; the twins were more often Type B (secure/balanced) than the singletons, and on the basis of the parental reports, singletons had significantly more behavioral and emotional symptoms than the twins.

Beck CT [12] Meta-synthesis of qualitative research on mothering multiples during the first year of life refers to bearing the burden of child care, riding the emotional roller coaster, lifesaving support, striving for maternal justice, and acknowledging individuality. Beck CT [13] observed that, during the first year after delivery, putting one's life on hold was the primary social and psychological problem for mothers of twins. She described the situation in terms of themes such as power drain, pausing one's own life, striving to relax, and resuming one's own life. Major depression occurs in one-third of pregnant women expecting twins [39]. Such mothers have been shown to have significantly higher levels of parenting stress and depression than mothers of singletons, and were significantly more likely to find parenting difficult and significantly less likely to obtain pleasure from their child $[40,41]$.

Most basic childcare tasks, such as feeding more than one child of the same age and sleeping arrangements for more than one child, are challenging $[8,9,15,18,42,43,44]$. It is also necessary to organize daily life and housework $[8,9]$. The need for support and special information from social and health care professionals in multiple-birth families has been reported in previous studies. $[8,11,12,13,16,29,38,45,34,46]$.

\section{The aim}

This article highlights some aspects of supporting multiple-birth families from the point of view of parents of twins and social and health care professionals. The main aim of this article is to deepen understanding of these phenomena, examining the need for support from three different perspectives, showing how the participants experienced the phenomena.

\section{Participants}

\section{The parents of twins}

Nineteen parents of twins, 5 months to 5 years old, participated in the present study. The mothers' ages ranged from 26 to 40 and the fathers' ages from 26 to 45 . They were married professionals from academic and non-academic backgrounds and lived in cities or the countryside. Seven mothers took care of their children at home, three worked outside home, and two were unemployed. Six fathers worked outside home and two on their own farm. All of the parents selfreported their twins as mono- or di-zygotic. All of the twin pairs were non-identical; only one of the parents was not sure about that. Five of the multiple-birth families also had siblings aged 3 to 17 . Only one family had a child younger than their twins.

The social and health care professionals; Public health nurses and family care workers

Eight public health nurses, aged between 35 and 58, and eleven family care workers, aged between 34 and 60, participated in the present study. The public health nurses' work experience in maternity clinics (prenatal) ranged from 2 months to 3 years, and their experience in child health clinics, from 5 to 26 years. All of these workers were trained as public health nurses; one was also a midwife and one a practical nurse. The family care workers' experience of working with clients in their homes ranged from 4 to 22 years. Most of them were trained in health and social care; some only had training in social work; many of them also had special training in family care. The duration of interaction was either short-term, with only a couple of visits, or for a longer period of up to three years.

\section{The data}

The data consist of the responses of the participant groups - parents of twins and social and health care professionals - and the notes of the researcher. The data for the parents $(n=19$, mothers $=12$ and fathers $\mathrm{n}=7)$, the public health nurses $(\mathrm{n}=8)$ and the family care workers $(\mathrm{n}=11)$ were collected through open-ended interviews and subsequent written responses sent to the researcher. All the participants themselves decided on the time of interviews, which were all conducted by the researcher herself, who was welcomed into multiple-birth family homes. All the open interviews began with the researcher requesting these parents to tell her something about support for multiple-birth families. The support of multiple-birth family is intertwined with everyday life. Later the researcher encouraged parents to describe and exemplify. The open interviews with social and health care professionlas began with them describing support for multiple-birth families, and, during the interview, they provided examples. The interviews took one and a half to two hours, were tape-recorded after obtaining parents' permission, and transcribed verbatim.

\section{Ethics}

Conducting a literature review led to the discovery of a gap in this research area, which ethically justifies the current study. It is important to hear different perspectives in order to gain a better understanding of this little-researched topic. It is also important to respect the participants' experiences; their experiences and knowledge are needed for understanding the perspectives of both professionals and parents, as well as for developing nursing care. All the participants 
were recruited to the study on obtaining a positive statement from the University Hospital's Ethics Committee and from the respective clinics. Only multiple-birth parents with experiences of such parenthood and professionals with experience of working with multiple-birth families were included. All the participants were provided with all requisite information, including the opportunity to withdraw from the study at any time. Their oral and written informed consent was obtained. The participants' anonymity was guaranteed, with only the researcher knowing their real names and which data belongs to which participant. The researcher interviewed all the participants face-to-face at the parents' homes or the professionals workplaces and analyzed the data.

\section{Data analysis}

The holistic approach depended on understanding the research material and participants' experiences. The researcher listened to the tapes of each interview and read the transcripts several times, and discovered some significant experiences of the participants. Various themes arose from the interviews. The researcher reflected on each sentence uttered by each participant and reported how the participant felt during the experience. In the selective and detailed phase, the researcher chose the best examples of participants' direct quotations, and rewrote every experience of each participant. The analysis then proceeded to the identification of essential themes for the experiences of the parents, public health nurses and family care workers. The researcher combined these essential themes and organized the phenomena for a disciplinary understanding. Table 1 describes the phenomena from the three different perspectives of the participants.

\section{Results}

This article presents the participants' experiences in their own words. Hearing their voices gives us insight into the life of a multiplebirth family and their need for support, viewed holistically from the perspectives of the different participants.

Table 1. Three perspectives on the lifeworld of multiple-birth families and their needs for support.

\begin{tabular}{|c|c|c|}
\hline Participants & Phenomena & Themes \\
\hline \multirow[t]{3}{*}{ Parents of twins } & A state of constant vigilance & $\begin{array}{l}\text { Two babies call, two babies need } \\
\text { The day and night rhythm is lost } \\
\text { The lack of information is trying }\end{array}$ \\
\hline & $\begin{array}{l}\text { Ensuring that they can } \\
\text { continue to cope }\end{array}$ & $\begin{array}{l}\text { Need for an extra pair of hands } \\
\text { Longing for a moment of rest } \\
\text { Sufficiency of income }\end{array}$ \\
\hline & $\begin{array}{l}\text { Opportunities to share with } \\
\text { other people }\end{array}$ & $\begin{array}{l}\text { Close relatives as enablers } \\
\text { Meeting professionals } \\
\text { Talking to someone who has been } \\
\text { through a } \\
\text { similar experience and understands }\end{array}$ \\
\hline \multirow[t]{3}{*}{$\begin{array}{l}\text { Public health } \\
\text { Nurses }\end{array}$} & Recognizing the strain & $\begin{array}{l}\text { Listening to how they are coping } \\
\text { Supporting parenthood }\end{array}$ \\
\hline & Targeting special needs & $\begin{array}{l}\text { Highlighting the need for special } \\
\text { information } \\
\text { Accessible public health nurses } \\
\text { Demanding sessions }\end{array}$ \\
\hline & $\begin{array}{l}\text { Lightening the load of } \\
\text { daily life }\end{array}$ & $\begin{array}{l}\text { Support network of close relatives } \\
\text { and friends } \\
\text { Need for family care workers } \\
\text { Peer support provides understanding }\end{array}$ \\
\hline \multirow[t]{3}{*}{$\begin{array}{l}\text { Family care } \\
\text { workers }\end{array}$} & Support with coping & $\begin{array}{l}\text { Strengthening parenthood } \\
\text { Arranging rest time }\end{array}$ \\
\hline & $\begin{array}{l}\text { Making use of special } \\
\text { information }\end{array}$ & $\begin{array}{l}\text { Care guidance } \\
\text { Taking into account the special } \\
\text { challenges of having twins } \\
\text { Guidance on spending }\end{array}$ \\
\hline & Bringing security & $\begin{array}{l}\text { Easing the burden of daily life } \\
\text { Trust to share responsibility } \\
\text { Effective support network }\end{array}$ \\
\hline
\end{tabular}

\section{Voice of parents of twins}

A state of constant vigilance: Parents of twins describe their situation as a state of constant vigilance, which means giving attention to two children all the time. Without let-up there are two babies calling with needs that must be satisfied as quickly as possible. Here mothers describe their experience as trying to do their best but always being one step behind.

"The feeling of inadequacy as a parent is something I can't even describe. The babies need me all the time, one after the other, and as a parent I wasn't able to meet their needs. And the babies' needs won't wait, no... Excuses don't help when they are hungry - you have to feed them immediately."

"Every time I did something for one, the other one would need my attention... The first six months felt as though I didn't keep up with the needs of the children; I was always one step behind. It was round-theclock, continuous, non-stop work with the children."

Some mothers describe a situation in which they needed professional help and support regarding feeding. They felt abandoned while the need for help was great. A situation where one baby was crying hungrily, and the other baby was alongside, was for many mothers mentally exhausting. Mothers did their best to make time for the other baby.

“... any help whatsoever regarding the breastfeeding. I lay in one of those very narrow hospital beds and I was all exhausted. And then they just brought the babies and left them there..."

"... When you feed the one baby and the other is screaming next door, it was so stressful that I had to try to relax, and try to make sure there was enough breast milk for both babies... and I try to organize things by attending to the first baby secretly before the second wakes up and needs me."

\section{The day and night rhythm is lost}

Parents describe their experiences of taking care of two babies around the clock. The night-time of a multiple-birth family was filled with feeding and caring for the children, which continued in the morning and day. The night-time strain continued and parents did not have time to recover, which meant that tiredness started to accumulate, and later many recognized the signs of exhaustion. The parents woke up several times to take care of the children during the night in each family, when the twins ate at night and woke up between feedings or slept poorly between feedings. Some twins had completely different biorhythms, so that when one child was awake, the other slept and vice versa; at times, one child disrupted the other's falling asleep. Despite their own tiredness, parents tried to provide the best possible care for their children.

Mothers who were with the twins most of the time also had body pains. Continually lifting and carrying the children put strain on the body and increased repetitive stress-type injuries and pains.

“... soon I won't be able to lift [them] anymore, but of course I know I won't get any help from anywhere. How many with one child get repetitive stress injuries in the arm?"

"That first year, the children woke up countless times, like from four to ten times a night... so that sometimes I didn't have time to sleep in between, I just couldn't fall asleep. So chronic sleep deprivation marked the first year!... If one... is almost falling asleep and the other starts to fuss, then the almost-sleeping-one is no longer sleepy because the other distracts them." 
"Ofcourse being a mother is wonderful. With me it was caring for the children and doing other things without rest... I didn't have time to stop and breathe at any stage. But I love my children so very, very much and I did everything and my husband, too... in the end, I myself was dead tired, so tired... absolutely exhausted. I did absolutely everything for the children night and day."

The parents reported that gradually they found various ways of coping. They got used to the life of a multiple-birth family. A daily rhythm was established, the children were growing, were able to wait their turn, played together and didn't need looking after all the time. The family's life became more settled.

“... our rhythm was totally off, but over the years we've found it again... yes, we're managing and moving forward. The children are growing and I have more time to watch their games and other activities too."

\section{The lack of information}

Parents of twins were pleased that they had an opportunity to meet the public health nurse and felt they were welcome at the child health clinic. Monitoring the growth and development of the children was very important to the parents. On the other hand, parents felt that the guidance given by professionals was intended more for families with children of different ages; they would have wanted guidance specific to parents of twins and their own circumstances. In particular, they would have liked information on child care, breastfeeding/feeding and organising and coping with daily life. Some of the parents had got help at home from a family care worker, which they felt was targeted at precisely the things for which help was needed. The guidance at home was given in the everyday caring situation together with the parents.

"One child cries, at first it cries from hunger and then, after gulping down the food, it cries because its belly aches and then spits up and cries because it feels bad to spit up, and after that it cries because it's hungry as everything came out. How can such problems be solved..??"

"Yes, you can call the clinic and they surely try to do their best there. We, too, tried to establish a rhythm in caring for the children. We would have really benefited if, already during the pregnancy, we had been prepared... if we had been told about various situations... there would have been time for that. I think that the right advice would have helped our family, too, and made life easier."

"The family care worker took the children out, so I got some peace, made food without interruption and... together we took care of the children and she gave us advice at the right time."

\section{Voice of family care workers}

Making use of special information: Family care workers considered it important to guide families at home and give parents information in addition to caring for the children. Family care work performed at home enabled them to monitor and guide the parents' actions. In a multiple-birth family, this meant making use of special information since the same information given to families with children of different ages was, in the experience of family care workers, not found to work in multiple-birth families. The information had to be adapted and directed to a situation where the family had more than one child of the same age. Through guidance, both parenting and coping with daily life were supported, which was considered challenging and demanding in multiple-birth families, especially when the children were small.

"Right at the beginning, it's important that they are guided so that things are organized there at home and the children well looked after.
When I'm with the family, I see the situations already there. They should try to alternate feeding times so that the same child isn't always first.... Because feeding at the same time doesn't usually work yet. Everyone first has to learn that as a parent."

"Taking care of children is different in multiple-birth families, and one of the babies has to await its turn. It is impossible to carry and care for them at the same time... you have to choose which of the babies needs more care, which one to take first, and you can help the other baby await its turn passing the time with a toy..."

Family care workers felt that parents of multiples needed special information as well, taking into account the special challenges of having twins, in order to support the growth and development of both children. This meant, among other things, taking account of and allowing the individuality of the twins in daily life. The parents also wanted to ask the family care worker questions and talk with them.

"Exchanging opinions and experiences of things related to the care and upbringing of multiples."

"... grow up with their own personalities and in that way would be taken into account, along with supporting parenting. If a parent hasn't thought about it in that way, that everything mustn't be done in the same way with both children, as if according to some kind of formula, then they really won't develop so individually..."

"We notice that the other is never answering, and that is because the first is so fast to talk and answer, parents also need support in the twins' problematic stages. At first, they have resources. But when the next twin is in this problematic stage, parents may already be too tired."

\section{Voice of public health nurses}

\section{Recognizing the strain}

In the experience of public health nurses, monitoring parental stress was important. For professionals, this meant having a sensitive ear and monitoring how the parents were coping with daily life and child care. The nurses saw the situation as different from that in families with children of different ages.

"It is a big change, the birth of a baby, and when two babies arrive, then there is, absolutely, this question of coping and how the family experiences the situation and how daily life will go. Multiple babies mean more work for the parents. So, in a way, if support is needed in taking care of just one baby, then... it's double the amount of support!"

Public health nurses felt that parents appreciated the work they did and the opportunity to visit the child health clinic. Visits to the clinic enabled parents to get information on the children's growth and development and also allowed them to open up about their concerns to the public health nurse. Nurses were even surprised at how parents coped with daily life.

"... the expertise ... the health issues are OK, the question is checked and the parents don't need to worry. The parents here, too, certainly appreciate the opportunity to call and visit the clinic. They can also unburden their feelings and the details of their situation. Actually, I myself always had a bit of a skeptical feeling all the time, like somehow I was always asking, can you really cope, and really wondering, where do they find the resources?"

Preparing parents of multiples and supporting parenting already during pregnancy was considered important. This involved assessing the family's support network and providing the necessary home care. 
Professionals also encouraged parents to admit and talk openly about their family's need for help.

“... to consider beforehand what challenges being a multiple-birth family will bring and how they could, like, be prepared and maybe already think about, like in advance, from where we can harness the care assistance and very concrete relief for daily life. ... already then [during pregnancy] say that they must learn to ask for help, because we should, like, move away, like, from the model where people are basically used to the idea of coping on their own and being very independent, selfsufficient and capable."

Caring for the children and the need to coordinate daily life was felt to get easier as the children grew, which allowed the parents to concentrate on the children also otherwise than when caring for them. There was a wish that parents would have more experiences of joy and time to be with their children. Parenting was also supported by taking account of each child's individuality and guiding the parents to make individual choices.

“... during the baby period, they're up to their eyes in work, then, later, it's easier to see how lovely that there are two and how they are nevertheless individuals and different and they are important to each other... to be absorbed in talking and playing and being face to face and that for that, too, there would be time... they should also have the right to that kind of pleasure and enjoyment of their own children ..."

"... even those six-month-olds, they already start to have a slightly looser daily rhythm and it's maybe a bit easier to move them towards the same rhythm, so that they would have their afternoon nap at the same time and the same feeding times and it would maybe be possible to feed the two children at the same time and then maybe it gets to the stage where they enjoy, like, being with each other on the floor with their toys, and in that way things may get a bit easier."

"... and you really mustn't do everything in the same way with both children, according to a certain pattern, but so they really develop as individuals ... then the comparison too, one may be a bit sharper and then the other has more abilities and one grabs your hair a bit more... one of them, say, to the sports club or [the other] to the music club ..."

\section{Voice of parents of twins}

\section{Ensuring that they can continue to cope}

All the parents emphasized the importance of ensuring that they can continue to cope. The demands of daily life made them feel the need for an extra pair of hands. The situation came as a surprise; the parents hadn't anticipated how much work there would be. Later, as family life became more settled, a mother recounted her feelings and expressed the view that the need for help should be assessed already during pregnancy. Help should be available as soon as mother and twins return home. In their busy daily life, the parents' wish was just to be with their children and focus on them without caring duties. Finding a rhythm made life easier and supported the parents' resources. Having help at home also made it easier for the parents to attend family group meetings, where they could share their experiences and get peer support. Fathers, too, were keen to attend family group meetings when on paternity leave.

"The help at home should have been arranged right from the start. I just had no idea how many things you have to do and also, besides the caring duties, feed two babies many times a day. A child doesn't wait. A child must be cared for immediately and then there are two to be cared for. We would have liked to just be with the children more. But we didn't have enough hands to do more."

"So you should almost, like, have a kind of rhythm, like, for the day and night, so that you just, so that you yourself could, say, just eat properly, and not just get a biscuit from the cupboard. When the hurlyburly begins, so there's a rhythm, so, er, yes, it's really that sort of concrete help that I, at least, think is important."

"We need family care workers' help with cleaning, making food and laundering. At first we went without food. Because of this non-stop caring, we didn't have time to cook. We need help also to attend family group meetings. You can meet other parents there, expecially when the father has his paternal leave. There are friends, and you can make new friends there!"

Having a family care worker in the home supported and strengthened parental coping, made daily life easier and allowed the parent to rest. A confidential care relationship between the parent and the worker was established over many home visits.

“... so I know that there will be one morning that is easier for me, so even if it's been a bad night, I don't need to dash everywhere, I can have a moment's peace and leave [the twins], now that they [family care workers] already know so well that I can leave [the twins] there, so would you mind dressing them and the diapers are over there."

\section{Longing for a moment of rest}

Mothers, in particular, felt that their strength gradually diminished. They tried to make sure that they could cope by finding moments of rest. This didn't mean only sleeping, but rather it was also important to leave the home for a moment and go to another environment. A moment of rest was personal time, even though it may have meant doing the family's grocery shopping. As the children grew, the need for help was understood from a different perspective as well.

"Sometimes I feel what I miss most are those 45 minutes to go shopping or to the library, just having a moment of my own, an opportunity to stop for a while."

“... now I realize... that if I was expecting twins now, then for the first six months I would have, like, if only possible, a home help or someone who would come, and like, just help... absolutely it would be, they would come quite regularly, say once a week and it would be for four hours or so. So for that time, I could sleep or maybe go out somewhere or really just getting away from things should be arranged... For example, the first year was such that I should have done that, it would have been worth it, it would have helped me cope better."

\section{Voice of family care workers}

\section{Bringing security}

Family care workers felt that their presence brought security to parents ("I think one big thing was just being present there. They derive a feeling of security from that.") Their presence was considered important because it directly eased the burden of daily life for parents. Family care workers were normally present in the homes, but some of them reported that their work also extended to the clinic, where they helped and listened to the advice given to mothers by public health nurses. In the home, they reminded the mother of the advice and, if necessary, went over it with her. This was particularly important if the mother was tired. A family care worker described her own work and how it was targeted especially to the time when the twins were newborns. 
Mothers should also be given the chance to recover from the pregnancy and birth. The help that was available was seen to have changed with changes in society.

"When the mother went to the health clinic with the twins, I also went there to help her take care of the babies, so she could concentrate on listening and had the chance to discuss with the public health nurse. I myself listened to their advice and later repeated and discussed them at home."

"... three months of stomach problems and they have eased and a daily routine has been established and the mother has had time to recover from the birth, that is, partly at least, but to achieve a mental balance..."

"Earlier... a family was given help entirely without it being requested, they were even offered help with housework. At that time, family work was important and necessary and just provided security for ordinary daily living, so it's a shame that this work for families with children is not done to the same extent anymore."

\section{Trust to share responsibility}

The relationship between family care workers and parents was based on mutual trust. Parents let the family care workers take care of the twins and their siblings. Family care workers were often also adult company for the mother and they talked about different things. The family care workers were especially concerned about not having enough time for the twins' siblings. The family care workers made daily life easier by doing and helping with housework.

"I release the mother from her charge and suggest that she has a shower. Often I feed the twins when one of the parents is asleep. The mother who had stayed awake all night, taking care of twins, was able to put in earplugs and go to another room to sleep."

"But when you have twin babies, parents feel that they haven't enough time with their siblings. These siblings were also jealous of the twin babies. When the babies needed care, at the same moment, the siblings solicited undivided attention. I took a nursing student with me..."

"When I'm with the family, it's nice to just chat about everyday things with the parents. At the same time, we take care of the children together and think about how best to help this family and what model would work for them in different situations. My experiences as a worker can even help me suggest and try something good again..."

\section{Effective support network}

Organizing an effective network strengthens multiple-birth family life. Others around them were important to parents. Grandparents mattered, but it was equally important that they could bodily fulfill their own requirements. It is important to have opportunities to meet and share daily life with other people and move outside the house while the family care worker helps at home.

"... naturally, life is easier if the family has a support network. Of course, they often need other people, especially when the children are small. And obviously it's important that there are people who genuinely want to help. The grandparents are often old and obviously they must be allowed to concentrate on just being with their grandchildren."

"Help from family care workers comes with no obligations. You do not have to be or feel indebted to anyone later."

\section{Voice of public health nurses}

\section{Targeting special needs}

Public health nurses' experiences showed that they recognized the family's need for special information. Nurses viewed guidance of parents as important and reported the concerns that led parents to contact the clinic. They recognized that nights were hard for a multiplebirth family and focused their advice on night-time arrangements and establishing a feeding routine. Attention was also paid to supporting the children's individuality. Providing concrete advice was not, however, easy for nurses. Their own capacity and means to help a multiple-birth family were considered limited.

"... the nights are restless ... what do we do when they eat at hourly intervals and, er, are crying and sleep for short periods in the daytime, too, and when one wakes up then the other wakes up too... coping-related issues... because they don't get any sleep themselves at all."

"As a public health nurse, you can't really do more than giving guidance on how they should prepare for the night... clear areas of responsibility ... it's even been agreed which things you should take care of and which things I'll take care of... multiple-birth-family babies would start sleeping... longer sleep periods, so in that way guiding breastfeeding or bottle feeding."

Public health nurses stressed the importance of treating the children equally and fairly. Recognizing the temperament of each child was considered important in supporting its development. "... treating them as equals, so that one is not held up as the good one ... since they are different, their personalities." Supporting a child's individuality was considered important. They also reported that parents expressed concern about how to give enough attention to their individuality.

\section{Accessible public health nurses}

Public health nurses considered it important that they were there for families and supported them by being contactable and through their own presence. Visits to the child health clinic were found to be important for parents. Information about the children's welfare and health, as well as the fact that they could call the clinic and ask about things, and that the nurse had time to listen, was important to the parents. Nurses used various ways of helping to support parents and many also felt that they could not have done more. In supporting the parents, it was considered important for nurses to be present and show sympathy and understanding.

"... the expertise ... the health issues are OK, the question is checked and the parents don't need to worry. The parents here, too, certainly appreciate the opportunity to call and visit the clinic. They can also unburden their feelings and the details of their situation."

“... I can't do anything in some situations, so it's enough that I give them my understanding... that half helps the person ... Listening is important, understanding can be shown, say with a word or a nod. Sometimes I have taken their hand or gone to sit next to them... Eye contact, too, can be support. On a weekday, even a surprising smile ... and time ... I try to organize them time to come together and when it is the easiest time for them. So the father can also come and help the mother."

\section{Voice of parents of twins}

\section{Opportunities to share with other people}

Parents considered it important that there were people around them with whom they could share their lives. Close relatives acted as 
enablers by giving parents an opportunity to do various things. Often this involved giving parents a chance to gather their strength - for example, by resting or getting help with housework. The involvement of grandparents also meant conversations between mother and daughter and the opportunity to receive support from the previous generation.

"Our parents arrived and began feeding the babies and changing their nappies. The twins' grandfather put the children to sleep in their prams. The babies would refuse to sleep if the pram didn't keep moving.. so he had to move the prams all the time."

"Mum went on leave from her job and came to help us. She came to take care of the grandchildren and me, too. We took care of them together and talked about many things and how best to do them. This was so important... and I and my husband, too, got hot meals. Mum helped with everything..."

\section{Meeting professionals}

Meeting professionals at the clinic was appreciated by parents. In particular, warmth shown by the public health nurse towards the whole family, friendliness and having their voices heard were important to parents, giving them the feeling that, at that moment, attention was focused on them and that their concerns were taken seriously. It was also apparent that, in particular, encouragement given to them by the nurse to cope with their situation was important. Public health nurses gave their undivided attention to the whole family, listening, asking and encouraging.

"It simply felt good that when you went there with the children, that the time was clearly for us, that they even asked how we were... like how is the father and how is the mother. And it wasn't just that they only measured and weighed the babies and checked and asked if they ate well.... They really saw our family as a whole... She is doing her work wholeheartedly and enjoys doing it. It was a very warm and cordial welcome there at the maternal and child health clinic in the health care centre."

"Our family really likes going to the clinic... the nurse listens... and you can call. I only want for the sort of advice that would make it easier for our family and especially when the children are so helpless and small, then everything would be important to make our situation easier. Because you yourself are so helpless as a new parent... "

On the other hand, parents reported that peer support was important - talking to someone who has been through a similar experience and understands - because their situation could only be understood by other multiple-birth families.

"Us and our issues can only be properly understood by someone who has experienced the same situation... at first hand. And that can only be another family with twins. It's so nice to talk to someone who immediately understands... Of course, you can get support from other families too... and that is naturally also important for us... but the feeling of inadequacy as a parent can only be understood by another similar parent. And we, for our part, also try to give support to all other parents..."

\section{Voice of public health nurses}

Public health nurses felt that there was a need to lighten the load of daily life for multiple-birth families through a support network, of close relatives and friends as well as outside help. Nurses had very limited means to provide multiple-birth families with concrete help, particularly if families did not have serious problems. However, nurses turned to family care workers, for whom they felt there was a need, especially with multiple-birth families. This would provide parents with a variety of help and also a chance to spend time with the babies.

“... even I can see that the mother is tired... I don't have any way of helping her, the only thing that can be done in the child health clinic is listening and discussing together and trying to think about and find the best solution. Sometimes there are close family members, like grandparents and relatives, who can come to help..."

"... there is also learning with regard to household work and when we know what the baby and two babies bring to the family... So, it is important that there is someone who can take care of daily routines at home, and that there is food, washed laundry, and we should make sure that both babies can spend time in their parents' arms..."

\section{Peer support provides understanding}

Public health nurses considered it important to provide parents with peer support. Society has changed, and families no longer have helpers in the same way as before, nor are the grandparents around as in the past. With the parents' consent, family details were exchanged, and multiple-birth families brought together. This ensured peer support for these special families.

"Peer support is really important for parents today precisely because, above all, families are so small, without many siblings. Then the grandparents may still be working. The social structure has changedpeople go to work."

"... we asked some parents of twins, the mother or father, if, as we have a new family with twins, so could I give them your details, and in this way or that families found each other already earlier, before there were these peer support groups."

\section{Discussion}

The life change brought about by the birth of twins was not fully anticipated by the parents [20] found that mothers were psychologically unprepared. It was difficult for them to meet the children's needs simultaneously, and they had more ambivalent and negative feelings than mothers of singletons. The present study shows that public health nurses recognized the need for parents to be prepared for parenting twins, but there was no special provision for this. Moreover, parents felt that most of the professional guidance they received was intended for parents with one baby. While they appreciated their visits to the child health clinic, they expected help appropriate to their special needs. They also wanted more opportunites to share their lives and feelings with others. After childbirth, the parents were provided with general information on infant care, but there was no support aimed specifically at multiple parenting. Support, which concentrates on guiding parents to assess their own coping skills and recognize their need for help is important $[8,16]$. Bryan E [28] states that such parents need education before, during and after multiple birth $[8,16,17,21,31]$. Parents tried to do their best, but mothers of multiples suffer from maternal overload, experiencing considerable stress and fatigue [47], which drains their physical and mental reserves. There is the need for supporting the health of parents, especially mothers $[8,9,27,47]$. Most of their time is taken up with child care, and they have only a few moments for pleasure, fun and playing with their children $[8,32]$. This was also described in the present study; the parents wanted to be able to spend more time with the twins without hurry and also give more attention to their siblings. Family care workers, too, were concerned about the lack of time for siblings. 
In the present study, parents would have liked more information about everything from pregnancy, childbirth and breastfeeding to caring for and raising twins and coping with everyday life as a multiplebirth family. Previous research has shown that help from the spouse is greatest after mother and babies return home, but diminishes by the end of the second month [33]. Garel M, et al. [47] report mothers' difficulties, which related to home help, social isolation, the marital relationship and the relationship with the children, all of which affect the mother's own emotional wellbeing [47]. Systematic review shows that that parents of multiples experience heightened symptoms of depression, anxiety, and parental stress that parents of singletons. Major depression occurs in one-third of pregnant women expecting twins and is associated with higher levels of stress and lack of social support [39]. The couple's relationship has been found to be one of the most important resources as experienced by the parents of multiples [8] and both family care workers and parents felt it was important to talk about the relationship [9,31]. Accordingly, professionals should give more attention to strengthening the couple's relationship in order to help them support each other in coping with their stressful situation. Parents were hungry for information during pregnancy, and this provides professionals with a good opportunity to prepare and guide parents and thereby promote the health and wellbeing of the whole family [8,9,31]. Leonard LG [11] identify four interrelated principles of good practice that are vital to the care of multiple-birth families: the involvement of a range of disciplines, of the family and of the multiplebirth community; the provision of specialized care; coordinated services; and the building of family competency including the capacity to make informed decisions. Preparation should include education on the special aspects of multiple pregnancy and parenting using multiples-focused resources, health promotion and risk modification strategies, infant care and feeding, child development and advice on securing help and support while ensuring family participation in all care decisions.

In the present study, feeding was especially hard for mothers because of the lack of adequate information and guidance from social and health care professionals after birth. Gromada KK, et al. [48] state that health professionals need additional knowledge and skills if they are to provide appropriate assessment, intervention, and support when mothers breastfeed twins or higher-order multiples. Good prenatal preparation and postnatal help and support are essential for successful breastfeeding [11]. Feeding more than one child is problematic and demands much from the mother $[9,12,13,15]$. Garel $\mathrm{M}$, et al. [46] describes the helpfulness and authoritativeness of babyfeeding information for women pregnant with twins. Leonard LG [11] recommend that mothers should be reassured that it is possible to breastfeed two or more, and state that good antenatal preparation, specific to feeding multiples, is essential. They also emphasize that; besides the nutritional and immunological benefits, breastfeeding facilitates the mother-infant attachment by enabling the mother to build a close relationship with each infant. This is an important aspect when giving professional guidance to parents, remembering that the mother may not have enough milk and thus have to give the babies infant formula or human donor milk, too. There is also a lot of information and training available from national multiple-birth organizations and their support groups $[5,6]$. A previous study found that mothers developed egalitarian strategies - for example, changing the order in which the babies were fed [32]. Professionals can guide parents in feeding by showing them how to use a feeding pillow, suggesting feeding the babies together or alternating them, helping the other child wait with a toy, music or by rocking the baby carriage or stroller with their foot, or by asking for help from the father, grandparents, relatives or outsiders.

The father's help with childcare is needed immediately, which may make it even more natural than with one child. It also promotes the development of a closer bond between parent and child [36,38]. Fathers want to take part in child care [8], although when looking after the newborns alone they felt uncertain about their own ability to cope $[8,9,11]$. Giving the twins individual attention has been found to be difficult for parents $[27,49]$. Previous studies reported that the infants were cared for either by both parents together $[10,30]$ or by only one of the parents, the mother usually bearing the main responsibility for child care with the father's help [10,30], but parents also wanted other people to take care of the children [10]. In interaction situations, both children are present, and this can "disturb" the development of an interactive relationship since the parent(s) constantly has to attend to the needs of at least two children $[8,24,31]$. Previous studies reported that mothers who cared for their children individually coped best with mothering and had knowledge of the children's development and upbringing, whereas mothers who cared for the children as a "unit", routinely and according to the same rhythm were not able to take account of each child's personality and individuality and were the most depressed group of mothers. Individual treatment of the children is also possible, however, with the help of the father $[27,32,33]$. It has also been reported that multiple-birth infants were left alone more and looked at, talked to, and held less often than singletons [10]. The solution of "sharing twins" - a mother's twin and father's twin - has been found to promote individual development of twins and to relieve mutual rivalry between them since each has his/her own parent as an object of identification and attachment [36]. The father's involvement in childcare reduces the family's stress and enables each child to develop a bond with both parents $[36,48]$. In preparing parents for parenting of multiples, it is important to discuss the different ways of taking care of the children and how to organize their daily life. In particular, fathers should be encouraged to take part in childcare. Perhaps it would be possible for professionals to organize fathers' groups for this purpose.

In the present study, it was very stressful, especially for mothers, to hear one child crying when taking care of the other. Even the thought that the other child was there and needed their attention and help was in their minds most of the time even when the baby was sleeping. Parenting multiples meant being available for the chidren all the time "in a state of constant vigilance", which also caused tiredness. Parents very soon felt the need for an extra pair of hands. Previous studies reported that parents felt guilty because the children had to wait their turn to be taken care of $[8,42]$. Bolch CE, et al. [14] also reported the presence of guilty feelings, particularly regarding the inequality of care and attention they were able to provide to each child. In the present study, family care workers expressed concern about the ability of families to cope with the daily stress of caring for more than one child and tried to guide parents to lessen the difficulties of their situation. The overloading of the nursing tasks obliges the mother to adopt a precise organization in which she tries not to favour one of the twins to the detriment of the other. The mothers feel they will never be able to satisfy each child fully. "Doing the same thing" with both babies and an individual representation of each child presents itself very early in the mother's speech [34].

Recognizing the strain on the parents, public health nurses enquired how the parents were managing and supported parenting. But twin-specific information provided to parents was limited to supporting the twins' individuality. Parents themselves noticed that 
there was a need for special information in such families. For example, when providing information about a child's speech development, it is important to remember that the family environment and interaction has a significant effect, especially with twins [37]. In supporting twins' speech development, social and health care professionals should provide useful information for parents in everyday situations. If the family has outside help or a family care worker they can also concentrate on one baby at a time while a parent focuses on the other. This lets the parent spend a different kind of time with the child. Individual attention is also important for a child in later years too [9].

In the present study, having to constantly meet the children's needs and stay awake depleted the parents' resources and many of them reported chronic tiredness, even neuropathic pain. The situation led to the loss of a day and night rhythm. Outside help was highlighted as means of coping with daily life and gave parents a chance to rest. Mothers also encountered problems getting the twins to sleep [8,21,31]. Nurses who encounter mothers of twins in the prenatal or postpartum periods are in an ideal position to provide anticipatory counseling regarding the importance of sleep for both parents. Damato, et al. [20] suggest that recommendations for safe sleep may require tailoring for families with multiple infants. Nurses should cognizant of the need to tailor recommendations for safe infant sleep practices for parents [7].

Holditch David D [10] reported the daily burden of caregiving for the infants. It is not easy for parents when the children have different rhythms and one child is awake while the other is sleeping. The present study shows that finding a daily rhythm was wanted and needed by parents, and even finding a rhythm for one child helps them cope with daily life [8]. Parents should already have information to plan sleeping arrangements at the antenatal stage [11]. Support was needed to find a daily rhythm, $[8,16]$ solve problems with twins' sleep $[8,50]$, and parents' sleep $[7,19]$. There is also a need for support and advice for parents as well as guidance of midwives regarding the pros and cons of co-bedding for healthy twin babies $[18,19]$ Parents try different sleeping strategies such as taking turns to sleep, sleeping at the same time as the babies, taking naps and getting help from relatives. The present study shows that if one or both of the twins stay awake at night, there is clearly a greater need for outside help and family nursing care, which may also be required at night. Parents really expected and needed concrete advice to handle this kind of situation [8]. It is important for professionals to provide examples for parents to help them find the best solution in their own life.

Visiting the health clinic gave parents the chance to be heard, talk about and share their concerns, and find solutions together with the public health nurse. The nurses felt they were available for the parents and encouraged them to call, even with minor questions. Some of the nurses admitted that they lacked specialized knowledge in guiding multiple-birth families. Family care workers regarded their own work as important for multiple-birth families. They guided parents in child care and feeding, and organizing their daily lives, provided parents with an opportunity to rest or have time of their own, acted as adult company and conversation companions, helped with visits to the clinic and shops when required, and also did housework. Parents felt that family care workers provided help that focused on the needs of a multiple-birth family [31]. In this study, most of the parents would have liked more concrete guidance, which also meant that professions should understand and know the lifeworld of multiple-birth families. It is very important for professionals to discuss parenting with parents of multiples, prepare them for the stress of such parenting, and provide them with information on how to cope with this situation. Parents also stressed the need of peer support. In order for public health nurses to be able to guide such families, they clearly need more specialized training. Family care workers have to use all of their senses when working with such families at home and guiding them in practice. Perhaps it is time to increase the number of home visits by public health nurses and multidisciplinary collaboration as well as cooperate more with the parents.

There is a need for more evidence-based practice, which requires that social and health care professionals possess wide-ranging knowledge. Qualitative research provides us with highly individualized, subjective and context-bound evidence as the basis for practice. Knowledge obtained through qualitative research is important for the development of evidence-based nursing [51,52].

\section{Limitations}

Phenomenological hermeneutic studies respect natural enquiry into real contexts. Being unique, individual experiences do not lend themselves to generalization. Although the number of participants in the present study was small, the data were collected carefully, and this sample yielded rich experimental material. This study focused only on twins under five years of age, and did not deal with other multiple-birth families. Finally, this study lacks comparability, as this field is relatively unexplored.

\section{Conclusions}

Parents of multiples need evidence-based guidance and information from social and health care professionals. The information and guidance should support the children's growth and special programs can be develop parenting of multiples. Parents need information and guidance that helps them cope with the challenges of daily life, enabling them to rely on their own resources. Support should also be provided to strengthen the relationship between the spouses. The need for support should be determined in special situations, too, such as the death of a twin, parental separation and multicultural contexts. Parents should have their voices heard with regard to their own life situation. Peer support is important but it cannot replace information and guidance provided by social and health care professionals. Peer support has a clear added value when the parents want to take advantage of this opportunity.

In order to support multiple-birth families, special programmers can be developed that provide professionals with training while reinforcing their knowledge base. It must be borne in mind that multidisciplinary collaboration should be strengthened and utilized with this client group. The members of a multidisciplinary team should be aware of each other's expertise, so that in different contexts both new and familiar perspectives can be aired when the professionals are working in different environments such as a hospital, maternal and child health clinic and the family's home. In these situations, consideration must also be given to data protection-related issues and the parents' permission for transfer of personal data. The team should make use of the information provided by parents in peer support sessions. Information is required that should be increasingly individual and specific to the situations of multiple-birth families. I believe that a genuine interest in multiple-birth families, acting with awareness and working together will lead to the best outcome.

\section{Conflicting of Interests}

The authors declare no potential conflicts of interest with respect to the research, authorship, and/or publication of this article. The author 
discloses the receipt of the following financial support for the research: Ministry of Social Affairs and Health.

\section{Acknowledgements}

I thank all the participants for sharing their experiences with me. I thank my supervisors Professors Anna-Maija Pietilä, Arja HäggmanLaitila and Irma Moilanen. I am also very grateful to William Ansell for helping with the language revision of the manuscript.

\section{References}

1. Van Manen M (1997) Researching Lived Experience. Human Science for an Action Sensitive Pedagogy. London: Ont: Althouse.

2. Adams C, Van Manen M (2008) Phenomenology. Teoksessa: The Stage Encyclopedia of Qualitative Research Methods. Thousand Oaks, CA Sage Publications pp. 1-6.

3. Van Manen M (2014) Phenomenology of Practice. Meaning-Giving Methods in Phenomenological Research and Writing. USA: Left Coast Press.

4. Van Manen M, Adams CA (2010) “Phenomenology.” Edited by Peterson P, Baker E, McGaw B (Eds) In International Encyclopaedia of Education: Oxford: Elsevier pp. 449-455.

5. ICOMBO (2017) International Council of Multiple-Birth Organisations. Retrieved

6. The Finnish Multiple (2017) births Association.

7. Damato EG, Burant C (2008) Sleep patterns and fatigue in parents of twins. J Obstet Gynecol Neonatal Nurs 37: 738-749. [Crossref]

8. Heinonen K (2004) Dimensions and Possibilities in Multiple Birth Parenthood University of Kuopio. Abstract in English. Finland: Kopijyvä. Kuopio.

9. Heinonen K (2013) "The Lifeworld of Multiple-Birth Families from Being on Guard to Strengthening Parenthood" Phenomenological-Hermeneutic Study. Publications of the University of Eastern Finland. Dissertation in Health Sciences.

10. Holditch-Davis D, Roberts D, Sandelowski M (1990) "Early Parental Interactions with and Perceptions of Multiple Birth Infants." Journal of Advanced Nursing 30: 200-210.

11. Leonard LG, Denton J (2006) Preparation for parenting multiple birth children. Early Hum Dev 82: 371-378. [Crossref]

12. Beck CT (2002) Mothering multiples: a meta-synthesis of qualitative research. $M C N$ Am J Matern Child Nurs 27: 214-221. [Crossref]

13. Beck CT (2002b) "Releasing the Pause Button. Mothering Twins during the First Year of Life." Qualitative Health Research 12: 593-608.

14. Bolch CE, Davis P, Umstad MP, Fisher JR (2012) "Multiple Birth Families with Children with Special Needs: A Qualitative Investigation of Mothers' Experiences." Twin Res Hum Genet 15: 503-515.

15. Harvey ME, Athi R, Denny E (2014) Exploratory study on meeting the health social care needs of mothers with twins. Community Pract 87: 28-31. [Crossref]

16. Heinonen K, Moilanen I, Pietilä AM (2007) "Experiences of Support by Parents of Multiple Birth Children-An Interview Study. Nursing Science." Hoitotiede 4: 223-35.

17. Heinonen K, Häggman-Laitila A, Moilanen I, Pietilä AM (2016) "The Lifeworld of Multiple Birth Families." International Journal of Caring Science 9: 754-769.

18. Ball HL (2006) "Caring for Twin Infants: Sleeping Arrangements and Their Implications." Evidence Based Midwifery 4: 10-6.

19. Ball HL (2007) "Together or Part? A Behavioural and Physiological Investigation of Sleeping Arragements For Twin Babies. Caring for Twin Infants: Sleeping Arrangements and Their Implications.” Evidence Based Midwifery 23: 404-412.

20. Damato EG, Haas MC, Czeck P, Dowling DA, Barsman SG (2016) Safe Sleep Infant Care Practices Reported by Mothers of Twins. Adv Neonatal Care 16: E3-3E14. [Crossref]

21. Jahanafar S (2012) “Twins Co-bedding at Home. Parents' Perspective, Sleeping Pattern and Developmental Millstone.” Medical Journal 13: 13-18.

22. Moilanen I, Kunelius A, Tirkkonen T, McKinsey Grittenden P (2003) "Attachment in Finnish Twins." In Grittenden P, McKinsey Grittenden P, Claussen AH (Eds) The Organization of Attachment Relationships Maturation, Culture and Context, Cambridge: Cambridge University Press, pp. 125-140.

23. Penninkilampi-Kerola V (2006) Implications of Co-twin Dependence for Twins' Social Interactions, Mental Health and Alcohol Use. A Follow-up Study of Finnish Twins from Adolescence to Early Adulthood. Helsinki: University of Helsinki.
24. Trias T (2006) Inter-twin and Parent-twin Relationships and Mental Health: A Study of Twins from Adolescence to Young Adulthood. University of Oulu. Oulu: Juvenes Print Tampere.

25. Bryan E (2003) The impact of multiple preterm births on the family. BJOG 110 Suppl 20: 24-28. [Crossref]

26. Moilanen I (1996) Kaksosuus. In: Räsänen E. Moilanen I. Tamminen T. \& Almqvist F. (toim.). Lasten ja nuorisopsykiatria. Duodecim. Cummerus Kirjapaino Oy. Jyväskylä 72-5.

27. Goshen-Gottstein ER (1980) The mothering of twins, triplets and quadruplets Psychiatry 43: 189-204. [Crossref]

28. Bryan E (2002) Educating families, before, during and after a multiple birth. Semin Neonatol 7: 241-246. [Crossref]

29. Bryan E (2006) Multiple-birth children and their families. What nurses need to know. AWHONN Lifelines 10: 138-144. [Crossref]

30. Anderson A, Anderson B (1990) Toward a Substantive Theory of Mother-Twin Attachment. MCN.” The American Journal of Maternal/ Child Nursing 15: 373-377.

31. Heinonen K (2016) "Supporting Multiple Birth Families at Home." International Journal of Caring Science 9: 422-431.

32. Robin M, Josse D, Tourrette C (1988) Mother-twin interaction during early childhood. Acta Genet Med Gemellol (Roma) 37: 151-159. [Crossref]

33. Robin M, Corroyer D, Casati I (1996) Childcare patterns of mothers of twins during the first year. J Child Psychol Psychiatry 37: 453-460. [Crossref]

34. Josse D, Robin M (1986) "Some Aspects of Mother-Child Relationships Following the Birth of Twins." Early Child Development and Care 26: 1-18.

35. Manninen H (2003) Kilpailu äidin rakkaudesta - kaksoset ja varhainen vuorovaikutus Teoksessa: Niemelä, P., Siltala, P. \& Tamminen, T. 2003. Äidin ja vauvan varhainen vuorovaikutus. WS Bookwell Oy. Juva: 125-150.

36. Moilanen I, Pennanen P (1997) "Mother s child" and "father s child"among twins. A lognitudial twin study from pregnancy to 21 years age, with special reference to development and psychiatric diaorders. Acta Genet Med Gemellol 49: 219-230.

37. Rutter M, Redshaw J (1991) Annotation: growing up as a twin: Twin- singleton differences in psychological development. The Journal of Child Psychology and Psychiatry and allied disciplines 32: 885-895.

38. Tirkkonen T (2015) Early Attachment, Mental Well-being and Development of Finnish Children at Preschool Age. Twinship-Risk or Opportunity? University of Oulu. Graduate school. Oulu Tampere: Juvenes Print.

39. Benute, Nozzelle, Prohaska, Liao, De Lucia, et al. (2013) Twin pregnancies: Evaluation Major Depression, Stress and Social Support. Twin research and Human Genetics 16: 629-633.

40. Olivennes F, Golombok S, Ramogida C (2005) "Behavioral and Cognitive Development As Well As Family Functioning of Twins Conceived by Assisted Reprobuction: Findings from a Large Population Study." Fertility and Sterility 84: 725-33.

41. Leonard LG (1998) Depression and anxiety disorders during multiple pregnancy and parenthood. J Obstet Gynecol Neonatal Nurs 27: 329-337. [Crossref]

42. Beck CT (2006) Analyzing qualitative data. In Essentials of Nursing Research Methods, Appraisal, and Utilization. (6 ${ }^{\text {th }}$ Edn) Lippincott Williams \& Wilkins: 405-407.

43. Gromada KK, Spangler A (1998) "Breastfeeding Twins and Higher-Order Multiples." Journal of Obstetric, Gynecologic, and Neonatal Nursing 27: 441-449.

44. Hattori R, Hattori H (1999) Breastfeeding twins: guidelines for success. Birth 26: 37 42. [Crossref]

45. Van der Zalm JE (1995) Accommodating a twin pregnancy: maternal processes. Acta Genet Med Gemellol (Roma) 44: 117-133. [Crossref]

46. McKenzie PJ (2006) The seeking of baby-feeding information by Canadian women pregnant with twins. Midwifery 22: 218-227. [Crossref]

47. Garel M, Blondel B (1992) "Assessment at 1 Year of the Psychological Consequences of Having Triplets." Human Reproduction 7: 729-732.

48. Wenzes SJ, Battles CL, Tezanos KM (2015) Raisin Multiples: mental health of mother and fathers in early parenthood. Archives of Women's Mental Health 18: 163-176.

49. Fischbein S, Hallencreutz I, Wiklund I (1990) What is it to be a parent of twins?. Acta Geneticae Medicae et Gemellologiae 39: 271- 276.

50. Damato EG, Zupancic J (2009) Strategies used by parents of twins to obtain sleep. Appl Nurs Res 22: 216-220. [Crossref] 
Kristiina H (2017) Understanding the lives of multiple-birth families: Listening to the voices of parents and professionals

51. Denton J (2005) Twins and more--2. Practical aspects of parenting in the early years. $J$ Fam Health Care 15: 173-176. [Crossref]
52. Leonard Lg (1998) Depression and Anxiety Disorders During Multiple Pregnancy and Parenthood. Journal of Obstetric Gynecologic \& Neonatal Nursing 27: 329-337.

Copyright: $\mathbb{0} 2017$ Kristiina H. This is an open-access article distributed under the terms of the Creative Commons Attribution License, which permits unrestricted use, distribution, and reproduction in any medium, provided the original author and source are credited. 